\title{
A ÉTICA AMBIENTAL COMO UM CAMINHO PARA ENFRENTAR O DESAFIO DA PARTICIPAÇÃO E DA CIDADANIA NO CONTEXTO DA RACIONALIDADE JURÍDICA
}

Alana Ramos Araujo

Doutoranda em Ciências Jurídicas pelo PPGCJ/CCJ/UFPB. Professora assistente do Departamento de Ciências Jurídicas vinculado ao Centro de Ciências Jurídicas da Universidade Federal da Paraíba (DCJ/CCJ/UFPB). Mestre em Recursos Naturais pelo PPGRN/CTRN/UFCG. Contato: ara.alanapb@gmail.com

Belinda Pereira da Cunha

Professora associada da Universidade Federal da Paraíba. Professora dos Programas de Pós-graduação stricto sensu em Ciências Jurídicas da Universidade Federal da Paraíba; do Programa de Desenvolvimento e Meio Ambiente Regional - PRODEMA. Mestre e Doutora em Direitos Difusos e Coletivos pela Pontifícia Universidade Católica de São Paulo, com pesquisa na Universidade La Sapienza de Roma. Pós-doutorado pela Universidade Autônoma do México - UNAM, ambos aprovados pela CAPES. Contato: belindacunha@hotmail.com

\section{Resumo}

A sociedade moderno-industrial construiu um novo modelo de produzir, de negociar e de estabelecer as relações sociais num contexto de transformaçóes econômico-sociais em que o Direito exerceu - e exerce ainda - um papel central de legitimar e erigir em lei aspiraçóes, interesses, desejos e vontades diferentes, na maioria das vezes conflitantes. Este cenário constitui palco para a reflexão da cidadania e da participação no espaço democrático ante a racionalidade jurídica que não oferece soluçóes à questão da não-cidadania e da não-participação. Assim, situado no âmbito das ciências jurídicas e sociais, o trabalho parte da teoria geral do direito, perpassando pelo direito ambiental, pela economia, filosofia, sociologia e ética para ir em busca de resposta (s) ao seguinte problema: qual o papel da ética ambiental ante os direitos de cidadania e de participação no enfrentamento à racionalidade jurídica moderna? Para tanto, o objetivo geral é analisar criticamente a racionalidade jurídica moderna à luz da literatura pertinente ante o papel exercido pela ética ambiental no tocante às formas de participação e cidadania do povo. Metodologicamente, o trabalho segue abalizado numa abordagem teórica, através do método hermenêutico jurídico-sistêmico. A discussão levantada revela-se atual e pertinente ao contexto 
democrático em que as bases da cidadania e da participação são questionadas num cenário em que direitos humanos fundamentais são cada vez mais positivados, entretanto não acompanham sua efetividade na mesma escala de sua positivação.

\section{Palavras-chave}

Forma jurídica; Ética ambiental; Cidadania e participação.

\section{Résumé}

La société industrielle moderne construit un nouveau modèle de produire, d'échanger et d'établir des relations sociales dans un contexte de changement économique et social dans la qual la loi servis - et joue encore - un rôle central à légitimer et à ériger dans la loi les aspirations, les intérêts, désirs et des volontés différents, la plupart du temps contradictoires. Ce scénario est l'hôte de la réflexion de la citoyenneté et de la participation dans l'espace démocratique an avant à la rationalité juridique qui ne propose pas de solutions à la question des non-citoyens et les non-participation. Ainsi situé dans les sciences juridiques et sociales, le travail se commece a partir de la théorie générale du droit, en passant par le droit de l'environnement, l'économie, la philosophie, la sociologie et de l'éthique pour aller à la recherche de la réponse (s) à la problématique suivante: quel est le rôle de éthique de l'environnement au niveau des droits de la citoyenneté et de la participation à affronter la rationalité juridique moderne? L'objectif global est d'analyser de manière critique de la rationalité juridique moderne à la lumière de la documentation pertinente sur le rôle joué par l'éthique environnementale sur les formes de participation et la citoyenneté des personnes. Méthodologiquement, l'ouvrage suit une approche théorique, à travers la méthode herméneutique juridique et systémique. La discussion soulevée se révèle être à jour et pertinente au contexte démocratique dans lequel les fondements de la citoyenneté et la participation sont interrogés dans un scénario où les droits fondamentaux de l'homme sont de plus en plus positivisée, mais pas accompagner leur efficacité sur la même échelle de son affirmation.

\section{Mots-clés}

Forme juridique; Éthique de l'environnement; Citoyenneté et participation.

\section{Introdução}

A modernidade fundou o seu pensamento naquilo que chamou de razão, de ciência, de técnica, de conhecimento. Construiu um modelo de civilidade calcado em um momento histórico de grande efervescência, tal seja: a revolução industrial que alterou profundamente os modos de vida da sociedade. A sociedade industrial construiu um novo 
modelo de produzir, de negociar e de estabelecer as relaçóes sociais. Neste contexto de transformaçóes econômico-sociais, o Direito exerceu - e exerce ainda - um papel central de legitimar e erigir em lei as aspiraçóes, os interesses, desejos e vontades de indivíduos ou coletividades que gozavam de prestígio econômico, político e social. Tanto é que as revoluçóes burguesas norte-americana e francesa construíram documentos jurídicos a fim de reconhecer direitos universais que até hoje a todos não se aproveitam.

Foram elaboradas Cartas e Declaraçóes de Direitos que constituem, até a atualidade, em discursos jurídicos retóricos que visam convencer e alienar, mais do que concretizar, pois, sendo a Constituição e as declaraçóes um acoplamento estrutural entre Direito e Política, o uso da forma jurídica para legitimar interesses econômicos e políticos às expensas dos povos é uma forma nefasta de corrupção sistêmica que contribui para a dificultar e, por vezes, impedir os direitos de cidadania e a participação no espaço democrático.

Neste sentido, indaga-se: qual o papel da ética ambiental ante os direitos de cidadania e de participação no enfrentamento à racionalidade jurídica moderna?

Para buscar respostas a este problema, o objetivo geral do trabalho é analisar criticamente a racionalidade jurídica moderna à luz da literatura pertinente ante o papel exercido pela ética ambiental no tocante às formas de participação e cidadania do povo. Os objetivos específicos são: investigar a racionalidade jurídica moderna a partir dos seus construtos centrais; utilizar um caso normativo específico para demonstrar a argumentação da análise crítica descrita; conhecer o papel do saber e da ética ambiental diante da forma jurídica, da cidadania e da participação.

A partir de tais objetivos, metodologicamente, o trabalho segue abalizado numa abordagem teórica, através do método hermenêutico jurídico-sistêmico, no sentido de que se debruça sobre a análise da normatividade jurídica por meio da consideração de fatores, elementos e conhecimentos não jurídicos que interferem e se inter-relacionam num sistema complexo formado por diferentes saberes e interesses do tecido social.

Ato contínuo, o trabalho mostra-se numa discussão atual e pertinente ao contexto democrático em que as bases da cidadania e da participação são questionadas num cenário em que direitos humanos fundamentais são cada vez mais positivados, entretanto não acompanham sua efetividade na mesma escala de sua positivação, requerendo do cientista, do jurista, um olhar crítico a respeito da forma jurídica e de suas plataformas básicas de controle social.

\section{A Racionalidade Jurídica}

Esta seção dedica-se a ponderar sobre a racionalidade jurídica a partir de definiçóes do direito como técnica de controle social com o intuito de promover reflexáo a respeito 
das dificuldades de participação e cidadania no contexto da razão jurídica puramente normativa e socialmente isolada para em seguida discutir o papela na ética como um caminho para reestruturação deste desafio.

O Direito consiste numa ordem e num sistema de normas cuja unidade é constituída pelo fato de todas elas terem o mesmo fundamento de validade, que é uma norma fundamental da qual se retira a validade de todas as normas pertencentes a essa ordem (KELSEN, 1988). Esta ordem coativa, aduz:

Uma separação entre Direito e Moral, Direito e Justiça, significa que a validade de uma ordem jurídica positiva é independente desta Moral absoluta, única válida, da Moral por excelência, de a Moral [...] Tal pretensão não significa que o Direito nada tenha a ver com a Moral e com a Justiça, que o conceito de Direito náo caiba no conceito de bom [...] Se definimos Direito como norma, isto implica que o que é conforme-aoDireito (das Rechtmässige) é um bem [...] Isto significa que a validade de uma ordem jurídica positiva é independente da sua concordância ou discordância com qualquer sistema de Moral (KELSEN, 1998, p. 47).

Portanto, desta leitura, resta claro que o Direito, na teoria normativista kelseniana, compreende-se como norma posta e que a discussão do Direito deve dar-se no âmbito da validade, que é um aspecto formal, no sentido de que será Direito aquilo que for emanação do ato de vontade geral e condicional do legislador ou do ato de vontade particular e incondicional do intérprete do Direito.

Não obstante as variadas e, diga-se, apressadas críticas feitas a esta visão kelseniana do Direito, notadamente a dos jusnaturalistas e a dos sociólogos, às quais foram combatidas pelo Kelsen mesmo, Bobbio (2008, p. 53), numa atitude de examinar as críticas mais ferrenhas à Teoria Pura do Direito e de apontar as fragilidades de cada uma delas, conclui que esta resiste a tais críticas e advoga uma perspectiva também normativista do Direito.

Bobbio (1909-2004) define o Direito não como norma, mas como "um tipo de sistema normativo" (BOBBIO, 2011, p. 45), levando-se em conta que a norma jurídica só existe porque há um ordenamento jurídico ao qual ela corresponde e nele encontra a sua validade e a sua eficácia. Neste ponto, logo se percebe a sutil diferença entre o positivismo jurídico em Kelsen e em Bobbio: naquele o Direito é norma, neste o Direito é um sistema de normas; contudo, ambos definem o Direito a partir da norma, seja ela individuada seja ela tida em conjunto, daí serem autores da teoria normativista do Direito, à qual se reconhece a inegável e inafastável contribuição, ao tempo que se reconhece também a insuficiência da definição de Direito como norma ou como sistema de normas para dar respostas ao que o Direito se destina a servir: ordenação da sociedade.

Ainda no viés do positivismo jurídico normativista, pode-se mencionar Herbert Hart para quem o Direito é uma "instituição social e política complexa, com uma 
vertente regida por regras (e, nesse sentido, <<normativa >>)" (HART, 2005, p. 301), cujas regras jurídicas possuem "conformidade com princípios morais ou com valores substantivos" (HART, 2005, p. 312), denotando um inclusivismo no Direito de valores e princípios morais que estão postitivados, caracterizando-se, como ele mesmo se autodenomina, um positivista moderado.

A este viés normativista acrescenta-se uma outra visão do Direito, uma visão realista, aqui representada por Benjamin Cardozo segundo o qual o Direito nasce das relaçóes de fato que existem entre as coisas; a fonte dele está na utilidade social, na necessidade de que certas coisas resultem de determinadas hipóteses e a probabilidade mais forte de se encontrar o sentido deste objeto da ciência jurídica está nas exigências da vida social, cujo papel cabe primordialmente aos juízes, seja através da atribuição de sentido às normas, nas brechas e lacunas das fontes jurídicas, seja na criação de direito dirigido à utilidade social por meio do processo judicial (CARDOZO, 2004).

Este é o ponto em que começa a surgir uma perspectiva do Direito como uma racionalidade técnica de dominaçáo, uma vez que se ele deriva das exigências da vida social e se a vontade do legislador e do juiz devem ser dirigidas pelas necessidades da sociedade, tem-se que levar em consideração que as exigências sociais podem dirigir o processo de criação do Direito de forma manipulada, de forma induzida, conforme os interesses predominantes, tendo em vista que:

Lógica, costume, história, utilidade e os padrōes aceitos de conduta correta são as forças que, isoladamente ou combinadas, configuram o progresso do Direito. Qual destas forças vai dominar em cada caso vai depender, em grande parte, da importância ou do valor comparativo dos interesses sociais que assim serão promovidos ou prejudicados. Um dos interesses sociais mais fundamentais é que a lei deve ser uniforme e imparcial. Não deve haver nada em sua ação que cheire a preconceito, favor ou mesmo capricho ou extravagância arbitrários. A uniformidade deixa de ser um bem quando se torna uma uniformidade de opressão (CARDOZO, 2004, p. 82).

Nesta perspectiva, observa-se que o Direito começa a aparecer como instrumento de dominação na sociedade, no sentido de que se o Direito é utilizado para favorecer um grupo por razóes de lógica, de costume, histórica, de utilidade e de padróes de conduta, ocasiona uma ruptura com a uniformidade e imparcialidade esperadas e requeridas da norma e da decisão e esta ruptura pode dar-se no espectro da opressão e da dominação seja em Estado Democrático ou Estado Ditatorial.

Nesta vertente, há que se colacionar a tese de Ferraz Júnior de acordo com quem o Direito, além de proteger a sociedade do poder arbitrário e de preservá-la da tirania ditatorial, "é também um instrumento manipulável que frustra as aspirações dos menos 
privilegiados e permite o uso de técnicas de controle e dominaçáo que, por sua complexidade, é acessível apenas a uns poucos especialistas" (FERRAZ JÚNIOR, 2003, p. 32).

O autor antecitado toma como base para a sua teorização de direito como dominaçáo o sentido de dominaçáo cunhado por Max Weber em sua obra célebre Economia e Sociedade de 1921 na qual são descritos os três tipos de dominação.

Em Weber (1994, p. 33) "dominação é a probabilidade de encontrar obediência a uma ordem de determinado conteúdo, entre determinadas pessoas indicáveis" [grifo do autor], ou seja, obediência a ordens específicas dentro de determinado grupo de pessoas. Esta dominação tem que ter pretensão de legitimidade que seja "válida em grau relevante, consolide sua existência e determine, entre outros fatores, a natureza dos meios de dominação escolhidos" (WEBER, 1994, p. 140).

Os três tipos de dominação legítima nesta classificação weberiana são: dominação legal de caráter racional, que se baseia na crença na legitimidade das ordens estatuídas e do direito de mando daqueles que são nomeados para exercer essa dominaçáo; dominaçáo tradicional, que tem como base a crença nas tradiçóes vigentes no decorrer da história e na legitimidade daqueles que representam a autoridade; dominação carismática, que fundamenta-se na veneração extracotidiana da santidade, do poder heróico ou do caráter exemplar de uma pessoa e das ordens por esta reveladas ou criadas (WEBER, 1994, p. 141).

A tese de Ferraz Júnior (2003) de que o Direito é um instrumento manipulável por meio de técnicas e de dominação assenta-se na concepção da dominação legal, conforme a qual: o direito pode ser estatuído por meio racional com o intuito de ser respeitado pelos dominados; o direito é um conjunto de regras abstratas normalmente estatuídas com determinadas intençóes; quem obedece está obedecendo ao direito e náo à pessoa do senhor que tem o poder de mando (WEBER, 1994, p. 142).

À via do que foi dito, no tocante à constituição de regras que revelam - ou ocultam - determinadas intençôes, o direito como instrumento de dominação fundamenta-se no interesse de manutenção do status quo dos "segmentos hegemônicos da sociedade: ricos, brancos, homens, heterossexuais e outros. Em benefício da ordem social, são mantidas as desigualdades materiais que legitimam o exercício do poder opressor de alguns membros da sociedade sobre outros" (VIANNA, 2008, p. 120).

Ainda considere-se que, neste sentido, o Direito reflete as relaçôes econômicas por intermédio das normas abstratas e também do processo criativo judicial que, por vezes, regulamentam estas relaçôes consolidando o processo de dominaçáo operacionalizado pelo projeto jurídico burguês.

Partindo deste pressuposto de Direito como instrumento de racionalidade técnica de dominação social, política e econômica, institucionalizado por meio da autoridade e 
do poder do Estado através das instâncias jurídicas: norma e decisão judicial, discute-se a questão da participação e cidadania como desafios para a ética ambiental na racionalidade jurídica. Para adentrar neste debate, válido é compreender a forma jurídica que trata da questão ambiental e que implica a ética, a participação e cidadania.

O Direito Ambiental, como objeto de conhecimento do Direito define-se como “o complexo de princípios e normas coercitivas reguladoras das atividades humanas que, direta ou indiretamente, possam afetar a sanidade do ambiente em sua dimensáo global, visando à sua sustentabilidade para as presentes e futuras geraçóes" (MILARÉ, 2009, p. 815).

Ainda pode-se defini-lo como "conjunto de regras jurídicas de direito público que norteiam as atividades humanas, ora impondo limites, ora induzindo comportamentos por meio de instrumentos econômicos, com o objetivo de garantir que essas atividades não causem danos ao meio ambiente, impondo-se a responsabilização e as consequentes sanções aos transgressores dessas normas" (GRANZIERA, 2011, p. 6).

Acostando-se a esta noção de Direito Ambiental como indutor de comportamentos por meio de instrumentos econômicos, neste trabalho, admite-se como Direito Ambiental:

Um direito que tem por finalidade regular a apropriaçáo econômica dos bens ambientais, de forma que ela se faça levando em consideração a sustentabilidade dos recursos, o desenvolvimento econômico e social, assegurando aos interessados a participação nas diretrizes a serem adotadas, bem como padrốes adequados de saúde e renda (ANTUNES, 2005, p. 9).

Analisando os elementos comuns destas definições, pode-se extrair delas expressóes como: normas-regras-direito; regulação de atividade humana; instrumentos econômicos; sustentabilidade. Ao que estas expressóes indicam, parece o direito ambiental ter como finalidade a ordenação social no que tange a atividades de impacto econômico por meio da ordem jurídica com vistas à sustentabilidade.

Levando-se em consideração que esta seja uma visão um tanto quanto otimista, talvez até idealista, aproveita-se a frase significativa da terceira definição quando aduz que o direito ambiental tem por finalidade regular a apropriação econômica dos bens ambientais [grifos nossos]. Esta é a base, o ponto de partida para se analisar criticamente o direito ambiental.

De fato, reconhece-se como inegável que o direito ambiental tem como finalidade regular a apropriação econômica de bens ambientais, porém, não se considera aqui que isto se dê de forma orientada para a sustentabilidade, para o desenvolvimento social ou para serem adotados padróes adequados de saúde e renda. Considera-se, outrossim, que o direito ambiental regula a apropriação econômica de bens ambientais em decorrência do poder e da dominaçáo legal que exerce a elite econômica que o utiliza como instrumento 
de manipulação para operacionalizar o crescimento econômico, o lucro e o acumulo de riqueza através da exploração dos bens ambientais que se tornam recursos por meio do trabalho, da produção, da mercantilização e da circulação de mercadoria.

A isto, cognomina-se de direito do ambiente negociado, que significa que os meios econômicos e os poderes públicos, em regime de contratos, esperando cada um tirar o maior benefício possível, apelam a modos alternativos de regulação do ambiente, cujo cruzamento propicia um direito ambiental negociado de formas múltiplas em que "tratarse-á de negociar o próprio conteúdo da regra, muito antes da sua publicaçáo formal em édito [...] É a um feixe de necessidades diferentes e, por vezes opostas, que ele responde" (OST, 1995, p. 133).

Isto se vivifica ao se analisar a valoração econômica do objeto tutelado juridicamente pelo direito ambiental: o meio ambiente ou os bens ambientais. Neste esteio, em primeiro lugar, diga-se que a Constituição da República Federativa do Brasil de 1988, no artigo 170, determina que a defesa do meio ambiente é um dos princípios da atividade econômica. Interessante notar que os princípios da Ordem Econômica constitucional brasileira assentam-se na valorização social do trabalho humano, valorização social da livre inciativa e valorização social da livre concorrência, mas não se perfaz na valorização social do meio ambiente, ao contrário, pauta-se na defesa do meio ambiente como um mosaico de elementos com finalidade de exploração econômica, conforme se verá a seguir.

Além desta previsão constitucional, no que tange à legislação infra, tem-se que a Lei no 6.938 de 31 de agosto de 1981 que instituiu a Política Nacional do Meio Ambiente, em dispositivos diversos, consagrou o "perfil econômico" (D’ISEP, 2009, p. 147) desta política ambiental e, consequentemente, da proteção jurídica do meio ambiente com tal perfil.

Como exemplo, mencione-se que o artigo $3^{\circ}$ desta lei define "a atmosfera, as águas interiores, superficiais e subterrâneas, os estuários, o mar territorial, o solo, o subsolo, os elementos da biosfera, a fauna e a flora" como recursos ambientais, denotando que interpreta os "elementos setoriais do meio ambiente" (SILVA, 1992, p. 54) como recursos, como objetos de exploração econômica. Os bens ambientais considerados de per si não possuem destinação econômica; no entanto, quando são alçados à categoria de recursos é que ostentam esta finalidade (GRANZIERA, 2001; POMPEU, 2006). É destes - recursos ambientais - que se ocupa a tutela jurídica ambiental brasileira, já revelando a valoração econômica do meio ambiente e a utilização do direito ambiental como um instrumento de dominação da elite econômica.

Conformando-se a previsão normativa acima com a literatura pertinente, admite-se que a legislação protetora do macrobem ambiental "toma como objeto de proteção, não tanto o ambiente globalmente considerado, mas dimensóes setoriais", tais como 
solo, patrimônio florestal, fauna, ar atmosférico, água, sossego auditivo, paisagem visual (SILVA, 1992, p. 54).

Torna-se, assim, oportuno consignar que o direito ambiental setoriza-se por meio das políticas a ele relacionadas: política da biodiversidade, dos recursos hídricos, da poluição sonora, visual e atmosférica, de resíduos sólidos, de agrotóxicos, de atividades nucleares, do patrimônio genético (FIORILLO, 2012), além de política da educação ambiental, urbana, de saneamento básico, do desenvolvimento sustentável dos povos e comunidades tradicionais.

Dentro deste mosaico de políticas setoriais da macropolítica ambiental, uma que se pode colacionar neste trabalho, vez que se relaciona intimamente com a do meio ambiente, é a Política Nacional de Recursos Hídricos, instituída pela Lei no 9.433 de 8 de janeiro de 1997. Esta, numa visão global, ancora-se na seguinte estrutura: Título I que estabelece os fundamentos, os objetivos, as diretrizes gerais de ação e os instrumentos da gestão hídrica; Título II, que contempla os objetivos e a composição do sistema de gerenciamento, bem como dos órgãos incumbidos de executar a política hídrica; ao final, nos Títulos III e IV a lei em comento prevê infraçóes e penalidades e disposiçóes gerais e transitórias, respectivamente.

Esta lei cuida de estabelecer a política pública da gestão dos recursos hídricos no Brasil, da qual destaca-se, para os fins a que se destina o trabalho, o fundamento segundo o qual "a água é um recurso natural limitado, dotado de valor econômico" (ART. 1º, II). Esta valoração da água tem merecido ampla atenção científica desde a sua implementação. Produçôes acadêmicas de vários campos do conhecimento tem se debruçado sobre o tema, exemplificativamente a Economia, a Sociologia, a Engenharia Civil, a Administração, o Direito. Nestas tem se percebido uma tendência a aceitação e conformação com a valoração econômica da água e, inclusive, tem-se defendido que esta valoração constitui um mecanismo econômico de forte influência na democratização do direito de acesso à água (D'ISEP, 2010).

Obstante a esta visão, interpreta-se aqui que a valoração econômica da água estabelecida na política pública de gestão hídrica mostra-se como um fator central no processo de dominação da elite econômica brasileira por meio da apropriação econômica dos recursos naturais, neste caso, da água.

A política hídrica foi implementada no Brasil na década de 90, num cenário político, econômico, social e ambiental de grande complexidade, revelando profundas desigualdades sociais e estagnaçáo econômica (SACHS, 2003), depleção do meio ambiente natural, internalização da tendência mundial à mercantilização dos espaços da vida social, em especial através do discurso ambientalista, e dos recursos naturais, destacando-se, neste ínterim, a água (QUERMES, 2006). 
Neste sentido, o modelo de tutela jurídica da água, implementado numa década de influência ultraliberal (CAUBET, 2006), revela-se marcado pelos "mecanismos de mercado" (SILVA, 2010, p. 145), com "elementos claros de regulação econômica voltados para a formação de um mercado de águas" (NETO, 2009, p. 57) dentre os quais o valor econômico da água, a cobrança pelo uso dos recursos hídricos e a outorga pelos direitos de uso dos recursos hídricos. Para compreensão desta perspectiva, basta considerar o significado da palavra valor quando utilizado no contexto econômico.

Um bem, um item qualquer, uma mercadoria, no que atine ao seu valor possui valor de uso e valor de troca (ARISTÓTELES, 1985). Trabalhando este duplo aspecto Marx (1996, p. 57-58) afirmou que:

O valor de uso só tem valor para uso, e se efetiva apenas no processo de consumo [...] O mesmo valor de uso pode ser utilizado de modos diversos [...] Ainda que seja objeto de necessidades sociais, e estar, por isso, em contexto social, o valor de uso, contudo, não expressa nenhuma relação social de produçáa [...] Os valores de uso são imediatamente meios de subsistência.

Com base nesta elucidação sobre o primeiro aspecto de um bem, de um item ou de uma mercadoria e trazendo para a realidade dos bens ambientais, particularmente da água, observa-se que ela possui uma gama variada, talvez até infinita, de usos, de significados, de utilidade: dessedentação, hidratação, higienização, relaxamento; fins medicinais, recreação, embelezamento, simbolismo religioso, manifestação cultural. Veja-se que a água pode ter valor de uso nas celebraçóes religiosas como batismo na profissão de fé cristá; pode ter valor de uso recreativo como nos banhos de rios, açudes, mar, piscinas; pode ter valor de uso medicinal no intuito de evitar uma desidratação; pode ter valor de uso de sobrevivência no caso da dessedentaçáo; pode ter valor de uso cultural como no caso das comunidades indígenas para quem a água tem sentido divinizado; e por aí vão aspectos qualitativos e quantitativos do valor de uso da água.

Além deste, um bem ou mercadoria também possui valor de troca, ainda conforme Marx (1996, p. 57) que preleciona:

O valor de uso é diretamente a base material onde se apresenta uma relação econômica determinada - o valor de troca. O valor de troca aparece primeiramente como relaçâo quantitativa, em que valores de uso são trocáveis entre si. Totalmente indiferente, portanto, ao seu modo natural de existência, e sem consideraçấo à natureza específica da necessidade para a qual são valores de uso, as mercadorias cobrem-se umas às outras em quantidades determinadas, substituem-se entre si na troca.

Nesta perspectiva apontada por Marx, o bem ambiental, in casu, a água, ao possuir valor de troca transforma-se em recurso hídrico e passa a ter valor econômico, no sentido 
de que passa a ser um objeto negociável através da troca com outro valor de troca, no caso, a moeda, na quantidade correspondente de acordo com as regras de política econômica.

Ostentando valor de troca, a água torna-se uma mercadoria como outra qualquer, apropriável pelo sujeito que detiver a correlata quantidade de moeda que possibilita e viabiliza o mercado e a circulação da mercadoria e da riqueza que em torno dela se acumula. Em virtude disso, o valor da água implicado na norma protetiva não inclui o custo da saúde, o custo da recreação, os impactos sobre terceiros e os valores ecológicos $(\mathrm{CECH}$, 2013).

Este é o aspecto exaltado pela política pública da água, em melhores termos, pela política de gestáo dos recursos hídricos, ao imbricar à água o valor econômico, assumindo a posição "economicoideológica" (NETO, 2009, p. 57) do Estado brasileiro de valoração econômica do microbem ambiental água através da força impositiva da norma na qual fica tutelável juridicamente o valor de troca da água.

É neste ponto que se coloca a questáo crítica: quem ou quais sujeitos podem operacionalizar o valor econômico do bem ambiental, da água, por exemplo? Não resta dúvidas de que quem pode suportar o aspecto do valor de troca da água, como de qualquer outro bem ambiental, é a elite econômica e que a previsão normativa deste valor confere poder e dominação a este segmento social, dado o caráter impositivo do direito.

Assim, como se vê, o projeto jurídico burguês ocultado nas tacanhas normas econômicas do direito ambiental configura-se na valoração econômica do meio ambiente, como de todos os seus elementos setoriais, através de um sistema de abstraçóes que se qualifica como forma de dominação, tendo em vista que tais abstraçóes possuem coesão no direito positivo, o qual, para De Giorgi "es un sistema construido por uma estrutura en la que, a través de processos regulados, se aíslan determinadas formas del actuar y se fijan como válidas" (1998, p. 18). Ante esta noção do direito positivo:

Confirma-se o facto de que o direito do ambiente é um instrumento nas mãos dos decisores, mais do que um utensílio de salvaguarda da natureza [...] Finalmente, longe de impor um estatuto de conjunto das espécies e dos espaços naturais, que seria o garante da sua salvaguarda quantitativa e qualitativa, o direito do ambiente parece esforçar-se por retalhar os espaços em inúmeras zonas distintas e segmentar os recursos em múltiplos regimes particulares, às quais é oferecido um quadro jurídico complacente, que não censura em definitivo senão os abusos manifestos (OST, 1995, p. 129).

1 Tradução livre: "É um sistema constituído por uma estrutura na qual, através de processos regulados, são isoladas e fixadas como válidas determinadas formas de ação”. 
O Direito Ambiental, portanto, é um processo de decisão, de seleção e de escolhas, ligadas ao possível e ao tempo, definida por um processo formal que lhe confere validade e consequentemente existência e que coaduna um jogo de interesses econômicos no qual, em matéria de valor de troca, vence quem detém os meios para instrumentalizar este aspecto do valor da mercadoria.

Nesta racionalidade, portanto, é válido perpassar pelas ponderaçóes da conjuntura, dos elementos e das partes que interferem neste sistema jurídico, apesar de o mesmo incitar um isolamento e fechamento em relação a outros saberes científico e não científicos. Observe-se abaixo.

\section{Saber Ambiental: Participação e Cidadania}

Partindo, como marco téorico, do estudo de Enrique Leff (2000) a respeito da complexidade, interdisciplinaridade e saber ambiental; e traçando os antecedentes da questão ambiental e sua complexidade e da interdisciplinaridade, encontra-se que estas, no final do século XX, refletem uma crise de civilização e uma crise ambiental baseadas no fracionamento do conhecimento e na degradação ambiental, desencadeadas a partir de numa nova forma de fazer ciência fundamentada na racionalidade tecnológica.

Todavia, Leff aponta diversas contribuiçóes dadas pela Amércia Latina e pelo mundo no sentido de uma remodelagem do conhecimento e da educação em busca da construção de uma educação ambiental com uma visão holística capaz de restabelecer a relaçáo homem-natureza, através da utilização da interdisciplinaridade como caminho para a incorporação da dimensão ambiental no sistema educativo.

Desse modo, tornou-se possível uma mudança de paradigma segundo a qual abandonou-se a visão do meio ambiente como uma dimensão estritamente natural em favor de uma nova perspectiva em que o meio ambiente é o resultado de interaçóes entre natureza, economia, sociedade e cultura.

Nesse sentido, o autor defende que a interdisciplinaridade, como articulação das ciências naturais e sociais, gera o congrassamento do conhecimento científico com o saber e práticas não científicas, através da relação entre estas e as disciplinaridades. Diante disso, o autor suscita a crise ambiental como sendo resultado da crise do conhecimento e propóe estratégias epistemológicas para sanar esta problemática.

Para explicitar esta crise do conhecimento, o autor utiliza-se de um raciocínio paradoxal, partindo de referências diametralmente opostas, tais como: "a ciência e a tecnologia se convertem na maior força produtiva e destrutiva da humanidade" ou como "essa civilização do conhecimento é, ao mesmo tempo, a sociedade do desconhecimento". Esse paradoxo informa que a mesma civilizaçáo que busca cada vez mais intensamente a modernização 
tecnológica e o desenvolvimento econômico, através da Revolução Científica, o faz degradando brutalmente o meio ambiente, além de incentivar pesquisas disciplinares desconsiderando a visão holística e os variados saberes envolvidos na questão ambiental.

Portanto, segue o autor, a desvalorização do conhecimento ocorre em razão do parco investimento financeiro na educação, na ciência e na tecnologia em grande parte da América Latina e em função da falta de pesquisas interdisciplinares para o desenvolvimento sustentável e marginalização dos saberes tradicionais de uso sustentável dos recursos naturais.

Assim, o autor propóe uma estratégia epistemológica que enfrente ideologias teóricas que desconsideram o processo histórico da construção do conhecimento e dos saberes, para que sejam levados em conta os aspectos históricos, sociológicos, econômicos, culturais e naturais do processo de construção dos saberes científico e não-científico, de molde que seja erigido um saber ambiental abalizado em condiçóes interdisciplinares que gere articulaçóes entre ciência e a forma de adquirir o saber tradicional, popular e local, tendo-se em vista a sociedade como um elemento integrante de um ecossistema global.

Tais condiçóes interdisciplinares exprimem importante característica da interdisciplinaridade, qual seja, provocar a relação e as interaçóes entre as disciplinas e entre estas e os saberes não-científicos, possibilitando uma unidade do conhecimento.

Contudo, Leff menciona a possibilidade de uma perspectiva do conhecimento ainda mais retotalizadora do que a interdisciplinaridade: a transdisciplinaridade, que o autor defende como um canal de solução para problemas colocados pela interdisciplinaridade na sua atividade de recomposição dos saberes fracionados, tendo em vista que a transdisciplina congrega a relação entre o conhecimento disciplinar e o diálogo de saberes no âmbito da questão ambiental.

Em seguida, o autor expóe que a interdisciplinaridade, mais do que funcionar como método que inter-relaciona disciplinas, deve dialogar com saberes a fim de criar um novo conhecimento, um novo objeto de investigação. Dessa maneira, a interdisciplinaridade atua como um elemento em favor da colaboração entre ciências e saberes, cuja cooperação conduz à elaboração desse novo conhecimento.

É inconteste o caráter contributivo desta noção interdisciplinar para o processo de paticipação e cidadania, no sentido de provocar o debate a cerca da necessidade, do alcance e da importância da interdisciplinaridade para pensar e solucionar as questóes ambientais. Além disso, Leff (2000), reclama o surgimento ou o retorno do entrelaçamento e unificação do conhecimento científico e do saber e práticas não-científicas, compreensão esta que permite a abertura para a tão almejada visão holística no trato das demandas ambientais. 


\section{Racionalidade Ambiental: A Ética como um Caminho}

Esta questão da visão holística no trato das demandas ambientais imprescinde de um debate no âmbito da ética ambiental no contexto da racionalidade ambiental, cuja incursão ética implica uma abordagem ampla e profunda no manejo das questóes jurídico -ambientais, permitindo ao cidadão uma maior participação no processo democrático, na sua identidade como membro e parte da complexidade ambiental e no comportamento solidário voltado para a outridade.

Assim, em obra intitulada Racionalidade Ambintal, Leff (2006) faz uma exposição densa sobre o que denomina de projeto epistemológico da modernidade; contextualiza e problematiza este tema; faz uma indagação relevante e aponta uma possível soluçáo para a resolução do problema apresentado. $\mathrm{O}$ autor aborda a objetivação do mundo e a dominação do conhecimento científico trazidos com o Iluminismo, ou seja, com o predomínio da razão sobre os sentidos, os valores, os desejos, as culturas e afirma que um facilitador desta racionalidade é a globalização, a homogeneização do mundo e a hegemonia do estilo de vida trazido com a supremacia do conhecimento científico e tecnológico.

Para Leff (2006), esta objetivação do mundo, em lugar de criar modelos que representam a realidade, na verdade criou modelos que simulam a realidade e, nesta simulação, criou uma hiper-realidade, onipresente e caracterizada por afastar o real do mundo criado por esta racionalidade e causou a metástase do conhecimento, ou melhor, a generalização do conhecimento científico.

Assim, Leff diz que é necessário questionar esta racionalidade científica de modo a buscar uma nova racionalidade que permita a inclusão de significaçóes e o retorno da ordem simbólica para que a apropriação da natureza seja da ordem social e não apenas de ordem técnica e econômica e, com isto, seja buscado o desenvolvimento sustentável, vez que o projeto epistemológico da modernidade, embasado do crescimento econômico e na ditadura do conhecimento científico, promove, alimenta e perdulariza o desenvolvimento sustentado, o qual sustenta as práticas de dominação econômica da natureza, as quais são chamadas pelo autor de estratégias fatais do desenvolvimento, levando à crise ambiental, à escassez qualitativa dos recursos naturais, à pobreza, miséria e morte.

Diante desta problemática da complexidade ambiental, Leff obtempera que um caminho para a possível solução ou a busca pela solução da crise ambiental seja a construçáo de uma nova racionalidade, esta voltada uma política da diferença, da outridade, da postulação de valores, de significaçóes, de identidades, diversidades, diálogo de saberes, da ética ambiental, dentre outros, tal seja: a racionalidade ambiental. Esta enfrenta grande desafio, uma vez que, descrevendo a globalização econômica e a morte da natureza, proclamando, assim, que o domínio econômico e a técnica asseguram resolver a crise ambiental pelos próprios mecanismos de mercado, como a precificaçáo dos recursos 
naturais e pela tecnologia mesma, como as ditas tecnologias limpas e economias verdes, sendo que estas consistem muito mais em marketing ecológico do que reais soluçóes para a complexidade ambiental.

Assim, Leff (2006) critica o desenvolvimento sustentado pespegado pela tentativa de ecologizar a economia e aduz que a possível solução está na racionalidade ambiental. O autor busca em Weber e Habermas os marcos conceituais para desenvolver a sua racionalidade ambiental. Assim, o autor em tela constrói uma racionalidade ambiental formada pela racionalidade substantiva ou material; racionalidade teórica; racionalidade instrumental e racionalidade cultural, sendo que a articulação de todas estas na racionalidade poderá levar à uma nova racionalidade social e ressignificar a apropriação social da natureza.

Em Leff, a racionalidade substantiva ou material implica a postulação dos valores morais sociais na forma de apropriar-se da natureza; abrange, assim, as subjetividades; a racionalidade teórica é marcada pela construção de conceitos de alta relevância para orientar as estratégias a serem aplicadas para o desenvolvimento sustentável; a racionalidade instrumental insere os objetivos e meios eficazes à realização da racionalidade ambiental, através das políticas, dos instrumentos jurídicos e da tecnologia; a racionalidade cultural postula a inclusão das significaçóes culturais dos povos na relação homem-natureza, ampliando o campo de conhecimento científico para o diálogo de saberes.

Para Leff a gestão articulada de todos estes vieses da racionalidade erige uma racionalidade ambiental viabilizadora do desenvolvimento sustentável. Contudo, Leff aponta a dificuldade de realização da racionalidade ambiental, vez que esta se contrapóe à racionalidade econômica, fortemente guiada pela racionalidade formal e instrumental, pelo cientificismo, globalização econômica e objetivação do mundo, sufocando os valores, as subjetividades, as significaçóes e as diferenças.

Por isto autor afirma que é necessário haver uma ética ambiental para promover uma mudança de consciência e o retorno da ordem simbólica.

\section{Conclusões}

A sociedade está imersa num sistema que une, interliga e inter-relaciona várias partes. A partir deste construto, pensar o meio ambiente, é pensar em um sistema formado por um conjunto de partes que se relacionam entre si, seja de modo harmônico ou conflitivo. Neste sentido, o meio ambiente é o sistema por excelência que se perfaz por meio da junção de várias partes que se unem e se interligam através de relaçóes destrutivas e construtivas e em constante busca de reequilíbrio, cujo papel, paradoxalmente, tem cabido ao direito. 
O projeto jurídico da modernidade tem se revelado com o intuito de utilizar o direito como forma de legitimação de uma racionalidade técnica, instrumental, científica, baseada na fragmentaçáo do conhecimento e, consequentemente, junção de interesses tão variados e conflitantes que o próprio sistema jurídico náo consegue equilibrar, tais como as questóes que envolvem os direitos de cidadania e participação.

Contudo, a ética ambiental constitui um chamamento à uma nova forma de produzir o conhecimento, uma nova forma de enfrentar as problemáticas sociais a partir da interação dos diversos componentes do meio ambiente - naturais, sociais, econômicos, culturais -, a fim de buscar a viabilidade da interdisciplinaridade no campo ambiental, de resignificação das racionalidades, especialmente da racionalidade jurídica para que esta se reconstrua como uma racionalidade ambiental voltada para a legitimação de novos saberes e ampliação do campo e das formas jurídicas para outros campos do conhecimento e das formas de vida cultural de modo que o não-direito, em interação com o diereito possam reequilibrar o sistema jurídico-social desequilibrado pela inefetividade de direitos dos quais chamou-se a atenção neste trabalho para a cidadania e a participação no contexto democrático.

\section{Referências}

ANTUNES, Paulo de Bessa. Direito ambiental. 8. ed. Rio de Janeiro: Lumen Juris, 2005.

ARISTÓTELES. Política. Brasília: UnB, 1985.

BRASIL, Constituição da República Federativa do Brasil. Promulgada em 5 de outubro de 1988. Disponível em: <http://www.planalto.gov.br/ccivil_03/constituicao/ constituicao.htm>. Acesso em: 13 maio 2015.

. Lei Federal $n^{\circ}$ 9.433, de 08 de janeiro de 1997. Institui a Política Nacional de

Recursos Hídricos, cria o Sistema Nacional de Gerenciamento de Recursos Hídricos. Disponível em: <http://www.planalto.gov.br/CCIVIL/leis/L9433.htm>. Acesso em: 15 maio 2015.

BOBBIO, Norberto. Direito e poder. São Paulo: Editora UNESP, 2008.

. Teoria do ordenamento jurídico. São Paulo: EDIPRO, 2011.

CARDOZO, Benjamin. A natureza do processo judicial: palestras proferidas na universidade de Yale. São Paulo: Martins Fontes, 2004.

CAUBET, Christian Guy. A água, a lei, a política e o meio ambiente? 1 ed. Curitiba: Juruá, 2006.

CECH, Thomas V. Recursos hídricos: história, desenvolvimento, política e gestão. Rio de Janeiro: LTC, 2013. 
DE GIORGI, Raffaele. Ciência del derecho y legitimación. Colección Teoría Social. Ciudad de México: Universidad Iberoamericana, 1998.

D’ISEP, Clarissa Ferreira Macedo. Água juridicamente sustentável. São Paulo: Editora Revista dos Tribunais, 2010.

FERRAZ JUNIOR, Tercio Sampaio. Introdução ao estudo do direito: técnica, decisão, dominação / Tercio Sampaio Ferraz Junior. 4. ed. São Paulo : Atlas, 2003.

FIORILLO, Celso Antonio Pacheco. Curso de direito ambiental brasileiro. 13. ed. São Paulo: Saraiva, 2012.

GRANZIERA, Maria Luiza Machado. Direito de águas: disciplina jurídica das águas doces. São Paulo: Atlas, 2001.

Direito ambiental. 2. ed. São Paulo: Atlas, 2011.

HART, H. L. A. O conceito de direito. Lisboa: Fundação Calouste Gulbenkian, 2005.

KELSEN, Hans. Teoria pura do direito. 6. ed. São Paulo: Martins Fontes, 1998.

LEFF, Enrique. Complexidade, interdisciplinaridade e saber ambiental. In: PHILIPPI JR., A., TUCCI, C.E.M., HOGAN, D. J., NAVEGANTES, R. Interdisciplinaridade em ciências ambientais. São Paulo: Signus Editora, p. 19-51, 2000.

Racionalidade ambiental: a reaproriação social da natureza. Rio de Janeiro: Civilização Brasileira, 2006.

MARX, Karl. Do capital. In: Série Os Pensadores. São Paulo: Editora Nova Cultural, 1996.

MILARÉ, Édis. Direito do ambiente: a gestão ambiental em foco: doutrina, jurisprudência, glossário. 6. ed. São Paulo: Editora Revista dos Tribunais, 2009.

NETO, Deraldo Dias de Moraes. A natureza jurídica da cobrança do uso dos recursos hídricos: taxa ou preço público? Tese (Programa de Pós-Graduação em Direito) Universidade Federal da Bahia, Salvador-BA. 2009. Disponível em: <http://www. bibliotecadigital.ufba.br/tde_busca/arquivo.php?codArquivo=2144>. Acesso em: 18 maio 2015.

OST, François. A natureza à margem da lei. Lisboa, Instituto Piaget, 1995.

POMPEU, Cid Tomanik. Direito de águas no Brasil. São Paulo: Editora Revista dos Tribunais, 2006.

QUERMES, Paulo Afonso de Araujo. Contradiçóes nos processos de participaçáo cidadá na política nacional de recursos hídricos no Brasil: análise da experiência dos comitês de bacia. Tese (Programa de Pós-Graduação em Política Social) - Universidade de Brasília, Brasília-DF. 2006. 
SACHS, Ignacy. Inclusão social pelo trabalho: desenvolvimento humano, trabalho decente e futuro dos empreendedores de pequeno porte. Rio de Janeiro: Garamond, 2003.

SILVA, José Afonso da. Direito ambiental constitucional. 7. ed. São Paulo: Malheiros, 1992.

SILVA, Jairo Bezerra. As tramas da questão hídrica: uma análise da transformação da água num bem público dotado de valor econômico e dos comitês de bacia hidrográfica no Brasil. Tese (Programa de Pós-Graduação em Sociologia) - Universidade Federal da Paraíba. Paraíba, 2010.

VIANNA, Túlio Lima. Teoria quântica do direito: o direito como instrumento de dominação e resistência. In: Prisma Jurídico - Red de Revistas Científicas de América Latina, el Caribe, España y Portugal Sistema de Información Científica v. 7. n. 1. Enero-junio. 2008. pp. 109-129. Universidade Nove de Julho, Brasil. Disponível em: <http://www.redalyc.org/pdf/934/93412617008.pdf>. Acesso: 25 maio 2015.

WEBER, Max. Economia e sociedade: fundamentos de sociologia compreensiva. v. 1. 3. ed. Brasília: UnB, 1994. 